\title{
|1: $|1|$ \\ FADING CHARACTERISTICS OF PANCHROMATIC RADAR BACKSCATTER FROM SELECTED AGRICULTURAL TARGETS
}

NASA CR:

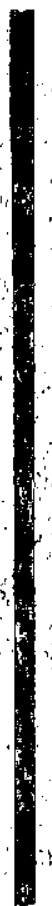

RSL Technical Report 177-48
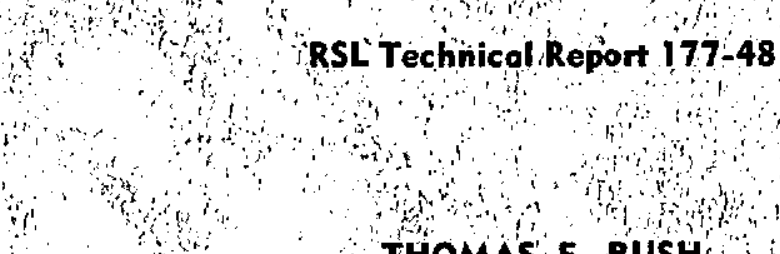

THOMAS F. BUSH

FAWWAZ T. ULABY

(NASA-CR-141686) FADING CHARACTERISTICS OF

PANCHROMATIC RADAR BACKSCATTER FROM SELECTED

AGRICULTURAL TARGETS (Kansas Univ. Center

for Research, Inc.) 39 p HC $\$ 3.75$ CSCL $17 I$

$\mathrm{G} 3 / 32 \quad \begin{aligned} & \text { Unclas } \\ & 12473\end{aligned}$

ง $75-18460$

December, 1973

Suppoited by:

NATIONAL AERONAUTICS AND SPACE ADMINISTRATION

Lyndon $B$. Johnson Spoce Center

Houston, Texas 77058

CONTRACT NAS 9-10261

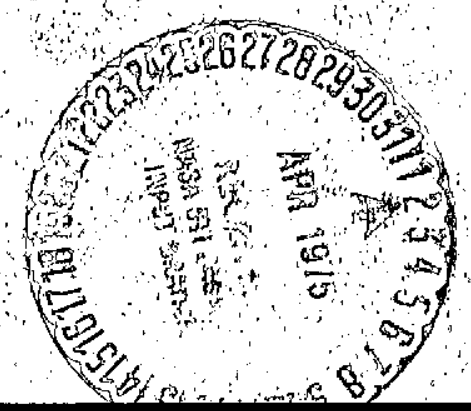

THE UNIVERSITY OF KANSAS CENTER FOR RESEARCH, INC. 


\title{
THE UNIVERSITY OF KANSAS SPACE TECHNOLOGY CENTER
} Raymond Nichols Hall

Telephone:

FADING CHARACTERISTICS OF PANCHROMATIC RADAR BACKSCATTER

FROM SELECTED AGRICULTURAL TARGETS

RSL Technical Report 177-48

\author{
Thomas F. Bush \\ Fawwaz T. Ulaby
}

December, 1973

\author{
Supported by: \\ NATIONAL AERONAUTICS AND SPACE ADMINISTRATION \\ Lyndon B. Johnson Space Center \\ Houston, Texas 77058 \\ CONTRACT NAS 9-10261
}




\section{TABLE OF CONTENTS}

$\underline{\text { Page }}$

ABSTRACT ......................

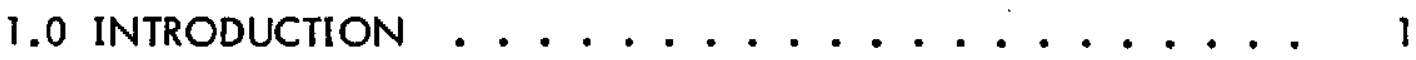

2.0 EXPERIMENTAL INSTRUMENTATION AND TECHNIQUE . . . 2

3.0 AVERAGING PROPERTIES OF PANCHROMATIC RADAR . . . 4

4.0 A THEORETICAL DESCRIPTION OF RADAR BACKSCATTER . . . 5

5.0 DETERMINATION OF THE NUMBER OF INDEPENDENT SAMPLES AVERAGED ............... 10

6.0 DATA INTERPRETATION .................. 13

7.0 CONCLUDING REMARKS . . . . . . . . . . . 19

APPENDIX A: Histograms of the Power Distributions of Radar Backscatter from Bare Ground, Soybeans, Corn and

Alfalfa.

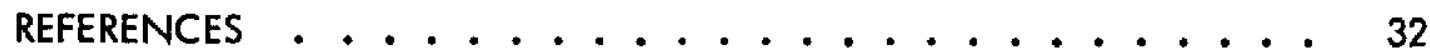




\section{ABSTRACT}

An experiment was performed to empirically determine the fading characteristics of backscattered radar signals from four agricultural targets at $9 \mathrm{GHz}$. After a short review of the statistics of Rayleigh fading backscatter, the data processing method and results of the data are analyzed. Comparison with theory shows adequate agreement with the experimental results, provided of course, the targets are modeled in a correct manner. 


\section{I.0 INTRODUCTION}

In studying the scattering of radar signals, fading is seen to play an important role. Fading, in the case of any coherent signal, is caused by the constructive and destructive interference of the signal components reflected by individual scatterers within a resolution cell. Thus, the phenomena of fading will be a function directly dependent on the target being studied.

This fading, or fluctuation, observed in the radar return introduces a significant complication in studying the scattering properties of a particular target. Making a single instantaneous measurement of scattered power will introduce errors since there are no means by which we can determine how much fading is indeed taking place. Thus it is necessary to make a number of measurements which can then be averaged so that the effects of fading are reduced.

The phenomena of fading appears in most radar studies and its effect produces a certain amount of uncertainty in the measurements being made. In the case of an imaging radar, the effect of fading is to cause speckle in the image. But it has been shown that even when very little averaging is performed by the imaging system, the eye-brain system performs an adequate amount of averaging when viewing a radar image [1].In detection radar systems, the problem of determining the probability of detecting a fading target has been studied extensively by Swerling [2] and a variety of other investigators $[3,4]$.

Because scatterometers are by definition calibrated devices used in determining scattering information on an absolute scale, fading poses particular problems. The question that must be asked is: How many samples of the scattered power must be averaged before certain confidence limits can be placed on the final average? This is often a difficult question to answer unless some a priori knowledge of the scattering properties of the target is known. This knowledge may be either theoretically derived or it may be based on data previously collected. de Loor [5] made an attempt to characterize the fading properties of certain agricultural targets although his experiments are limited to incidence angles larger than $80^{\circ}$.

In order to shed some experimental light on the subject of fading, it was decided to conduct an experiment to determine the fading properties of four selected agricultural targets. This report presents the results of this experiment. 


\subsection{EXPERIMENTAL INSTRÚMENTATION AND TECHNIQUE}

The radar used in this study was a wide band 8-18 GHz radar spectrometer scatterometer [6]. This is an FM-CW system employing two antennas (transmit and receive) mounted atop a 26 meter hydraulically operated boom. The boom is in turn mounted on a truck for mobility. The transmitted signal is frequency modulated by means of a triangular woveform with an amplitude adjusted to provide a frequency deviation of $400 \mathrm{MHz}$. Table 1 presents a summary of the basic system specifications with a system block diagram shown in Figure 1 .

\section{TABLE 1.}

\section{BASIC RADAR SPECIFICATIONS}

TYPE

Modulating Waveform

Frequency

FM sweep: $\Delta f$

Transmitter Power

Intermediate Frequency

IF Bandwidth

Antennas
$\mathrm{FM}-\mathrm{CW}$

Triangular

8-18 GHz

$400 \mathrm{MHz}$

$10 \mathrm{dBm}(10 \mathrm{~mW})$

$60 \mathrm{kHz}$

$3.58 \mathrm{kHz}$

$$
\begin{array}{ll}
\text { Height above ground } & 26 \mathrm{~m} \\
\text { Reflector Diameter } & 61 \mathrm{~cm} \\
\text { Feeds } & \text { Cavity backed, } \\
& \text { log perodic }
\end{array}
$$

$\frac{\text { Frequency }}{(\mathrm{GHz})}$

9 $\frac{\text { Calculated Antenna Gain }}{(\mathrm{dB})}$

31.2
Effective Beamwidrhs of Product Patterns (degrees)

Elevation

The system was calibrated against a Luneberg lens of known cross section. Because of rechnical difficulties, fading measurements were made only at $9 \mathrm{GHz}$ with $\checkmark$ polarization. 


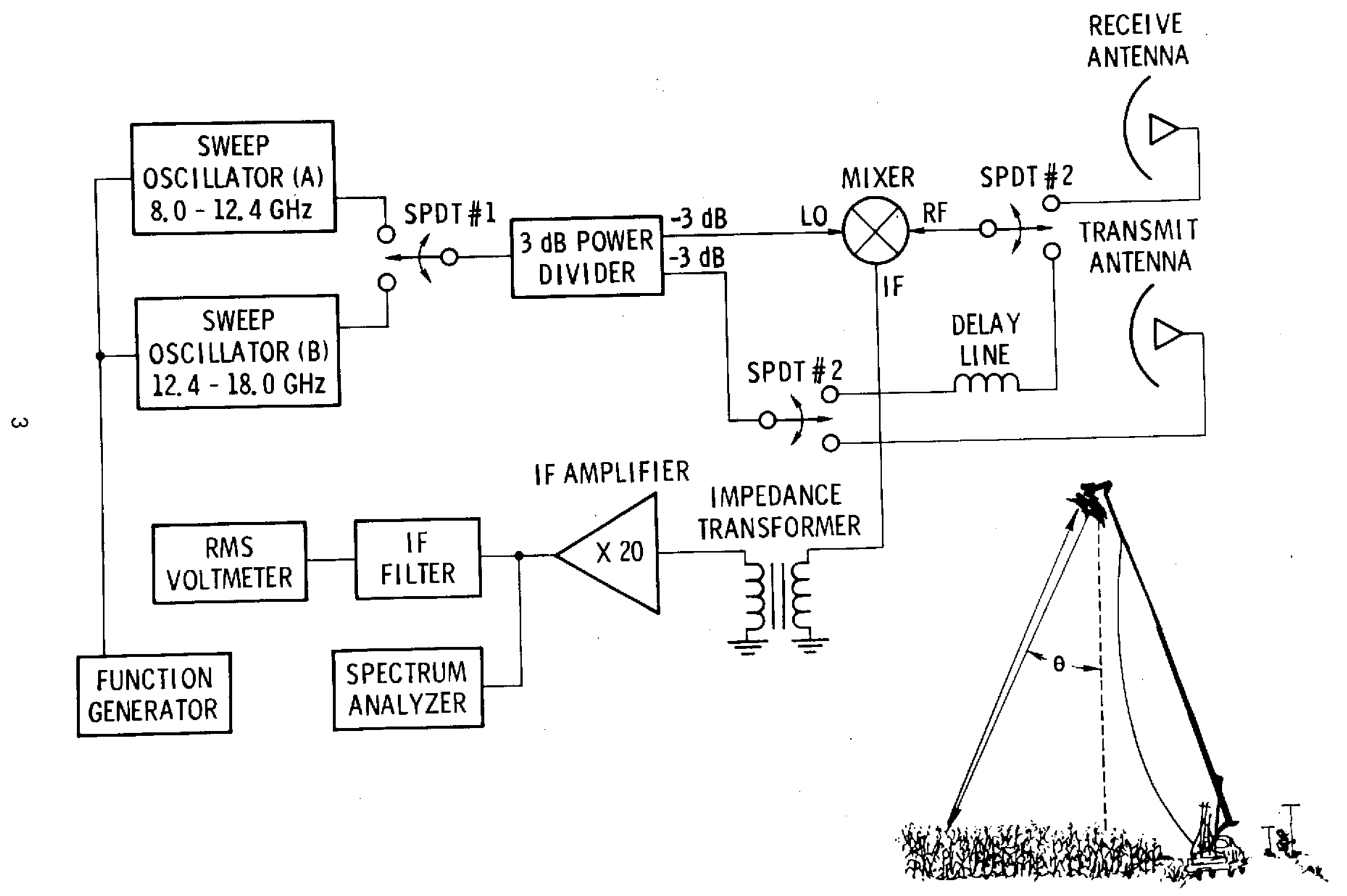

FIGURE 1. BASIC BLOCK DIAGRAM OF THE 8-18 RADAR SPECTROMETER. 
The measurements were made by locating the trucks at the edge of the field containing the target of interest. About 140 measurements were collected from each field at each of six incidence angles: $0^{\circ}, 10^{\circ}, 20^{\circ}, 30^{\circ}, 50^{\circ}$ and $70^{\circ}$. After each individual measurement the boom was moved a few degrees in azimuth in order to view an independent resolution cell. Non-overlapping cells were assumed independent. Targets studied were corn, alfalfa, soybeans and bare soil.

\subsection{AVERAGING PROPERTIES OF PANCHROMATIC RADAR}

The term "panchromatic", although usually applied to a multi-frequency signal in the visible portion of the spectrum can just as well be applied to a broad spectrum radar signal. Since the $8-18 \mathrm{GHz}$ radar used in the experiments under discussion is panchromatic it may be helpful to review some of the averaging properties of a panchromatic radar.

In 1963 Birkemeir and Wallace [7] considered the case of a target whose elements are uniformly distributed along a line of length $L$ as shown in Figure 2. After deriving an expression for the frequency autocorrelation function, they chose the first zero as the point of decorrelation. The corresponding frequency spacing for independence was found to be given by:

$$
\Delta f=\frac{150}{[\cos \theta} \quad \mathrm{MHz}
$$

where $\theta$ is the angle of incidence.

Other variations of this problem have been studied by Ray [8], Moore, et al. [9] and Waite [10] and in all cases the results yield expressions similar to Eq. la. Ray's [8] model is somewhat more applicable to vegetotion because his target is a volume having a maximum dimension $D$ (as measured radially from the antenna); his result takes the form:

$$
\Delta f=\frac{150}{D} \quad M H z
$$




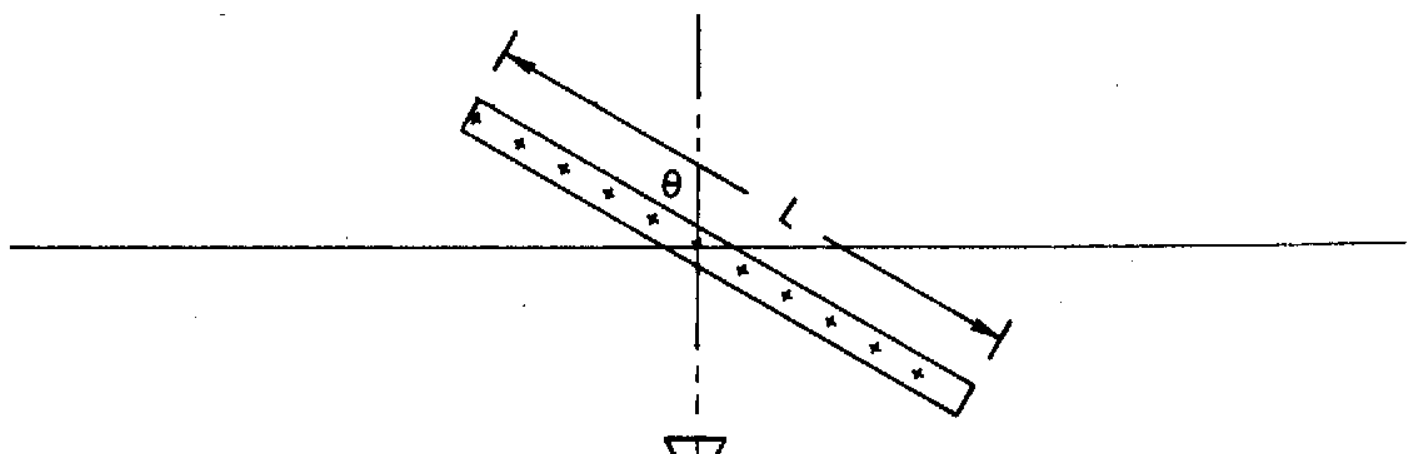

Figure 2.

\subsection{A THEORETICAL DESCRIPTION OF RADAR BACKSCATTER}

Before proceeding to a discussion of the experimental results, it will be helpful if we review some of the basic statistical properties of radar backscatter. Following a development provided by Beckmann [11] let us consider the returned E field, $E_{s}$, from a single scatterer:

$$
\begin{aligned}
E_{s} & =E \exp \left\{i\left(\omega t+\phi_{c}\right)\right\} \\
& =E e^{i \phi}
\end{aligned}
$$

where

$$
\phi \triangleq \omega t+\phi_{0}
$$

Now let us assume $E$ and $\phi$ to be random variables and that $\phi$ is uniformly distributed between $\psi$ and $\psi_{t}+2 \pi$. Consider the total E field returned from a collection of independent scatterers:

$$
E_{t}=R e^{j \theta}=\sum_{k=1}^{n} E_{k} e^{j \phi_{k}}
$$


where $n$ is the number of scatterers illuminated, $R$ is the magnitude of $E_{f}$ with angle $\theta$. The illustration in Figure 3 may be helpful.

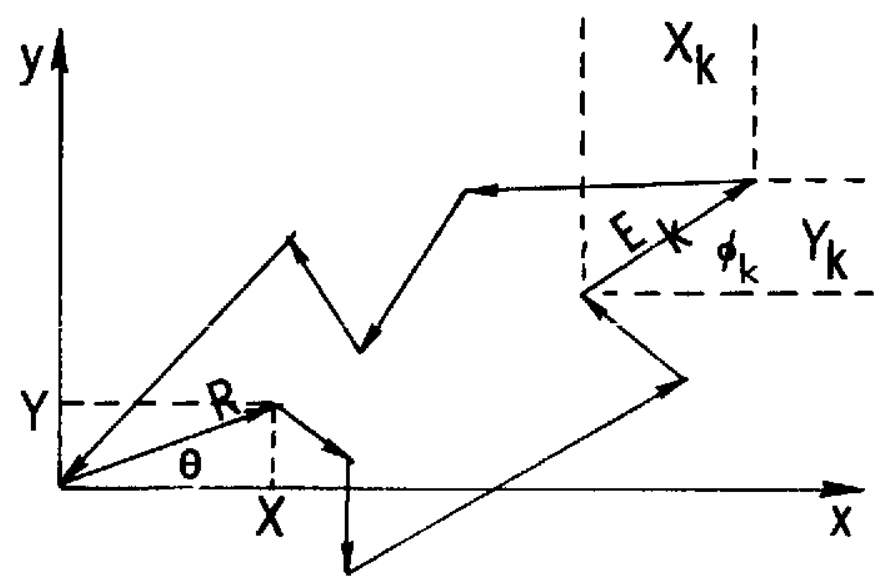

Figure 3.

We can easily see that the following is true:

$$
\begin{aligned}
& x=R \cos \theta=\sum_{k=1}^{n} E_{k} \cos \phi_{k} \triangleq \sum_{k=1}^{n} x_{k} \\
& y=R \sin \theta=\sum_{k=1}^{n} E_{k} \sin \phi_{k} \triangleq \sum_{k=1}^{n} Y_{k}
\end{aligned}
$$

Now, if we assume independence of $X_{k}$ 's and $Y_{k}$ 's and if we let $n$ become large we can apply the central limit theorem [12] and thus conclude that $x$ and $y$ are normally distributed with means:

$$
\begin{aligned}
& \langle x\rangle=\sum_{k=1}^{n}\left\langle E_{k} \cos \phi_{k}\right\rangle \\
& \langle Y\rangle=\sum_{k=1}^{n}\left\langle E_{k} \sin \phi_{k}\right\rangle
\end{aligned}
$$

Also, if the $E_{k}$ and $\phi$ are uncorrelated we can write

$$
\langle x\rangle=\sum_{k=1}^{n}\left\langle E_{k}\right\rangle\left\langle\cos \phi_{k}\right\rangle
$$




$$
\langle x\rangle=\sum_{k=1}^{n}\left\langle E_{k}\right\rangle \frac{1}{2 \pi} \int_{0}^{2 \pi} \cos \phi_{k} d \phi_{k}=0
$$

Similarly,

$$
\langle Y\rangle=0
$$

Likewise we can calculate the variances

$$
\sigma_{x}^{2}=\left\langle x^{2}\right\rangle=\sum_{k=1}^{n}\left\langle E_{k}^{2}\right\rangle\left\langle\cos ^{2} \phi_{k}\right\rangle=\frac{1}{2} n\left\langle E_{k}^{2}\right\rangle
$$

$$
\sigma_{y^{2}}^{2}=\left\langle y^{2}\right\rangle=\sum_{k=1}^{n}\left\langle E_{k}^{2}\right\rangle\left\langle\sin ^{2} \mathscr{\phi}_{k}\right\rangle=\frac{1}{2} n\left\langle E_{k}^{2}\right\rangle
$$

Thus, in accordance with the central limit theorem we can write expressions for the probability density functions of $X$ and $Y$ as follows:

$$
\begin{aligned}
& P(x)=\frac{1}{\sqrt{2 \pi} \sigma_{x}} e^{-x^{2} / 2 \sigma_{x}^{2}} \\
& P(y)=\frac{1}{\sqrt{2 \pi} \sigma_{y}} e^{-y^{2} / 2 \sigma_{y}^{2}}
\end{aligned}
$$

Now let's check to see if $X$ and $Y$ are correlated:

$\langle x \mid\rangle=\sum_{k=1}^{n} \sum_{i=1}^{n}\left\langle E_{k} E_{j} \quad \cos \phi_{k} \sin \phi_{1}\right\rangle$

By our assertion that the E's and $\phi$ 's are uncorrelated we can write

$\langle x y\rangle=\sum_{k=1}^{n} \sum_{i=1}^{n}\left\langle E_{k} E_{j}\right\rangle\left\langle\cos \phi_{k} \sin \phi_{1}\right\rangle=0$

since $<\cos \phi_{k} \sin \phi_{l}>\equiv 0$.

7 
Thus,

$$
\phi(x, y)=\frac{1}{z \pi \sigma^{2}} e^{-\left(x^{2}+y^{2}\right) / 20} \sigma^{2}
$$

Now, making the transformation to polar coordinates [13] we see that

$$
O(v, \theta)=\frac{v}{2 \pi \sigma^{2}} e^{-v^{2} / 2 \sigma^{2}}
$$

where

$$
\begin{array}{ll}
V^{2}=x^{2}+y^{2} & 0 \leq V \leq \infty \\
& 0 \leq E \leq 27
\end{array}
$$

Note that

$$
\left\langle V^{2}\right\rangle=\left\langle x^{2}\right\rangle+\left\langle y^{2}\right\rangle=2 \sigma^{2}
$$

Let $\left\langle V^{2}\right\rangle=2 \sigma^{2} \triangleq \alpha$

Thus,

$$
P(\nu, \theta)=\frac{\nu}{\alpha \pi} e^{-\nu^{2} / \alpha}
$$

and

$$
\begin{aligned}
P(v) & =\int_{0}^{2 \pi} P(v, \theta) d \theta \\
& =\frac{2 v}{\alpha} \omega-v^{2} / \alpha
\end{aligned}
$$

which is a Rayleigh probability density function.

Next we desire to determine the distribution of the return power. This is only a matter of making an appropriate change of variables :

$$
\left.W=K v^{2} / t\right)
$$

8 
where $W$ is the return power, $V$ is the envelope voltage amplitude of the received signal and $K$ is a proportionality constant. Dropping the constant $K$ for convenience and making the change of variables it can again be shown [13] that:

$$
P(w)=\frac{1}{20-2} \exp \left(-\frac{w}{20-2}\right)
$$

Although Eq. 21 is in reality an exponential density function it is often referred to as a Rayleigh power density function for obvious reasons.

On closer observation one will see that Eq. 21 is also a chi-square density function with two degrees of freedom. The chi-square density function is defined as:

$$
P_{n}(w)=\frac{1}{\left.2^{n / 2} \sigma_{r}^{n} \Gamma / \frac{n}{2}\right)} \exp \left(-\frac{w}{2 v_{r}^{2}}\right) w^{\frac{n}{2}-1}
$$

where $n$ is the number of degrees of freedom. The mean and the variance of the chisquare distribution are given as:

$$
=n \sigma_{r}^{2} \quad \sigma z=2 n \sigma_{r} 4
$$

where $\sigma_{r}$ is the standard deviation of the Rayleigh power density function.

Next let us consider the average of $N$ samples, each distributed, as we have shown, with a chi-square distribution with two degrees of freedom. We then have

$$
\bar{W}=\frac{1}{N} \sum_{i=1}^{N} W_{i}
$$

Consider $\quad \gamma \triangleq \sum_{i=1}^{N} k / i$

By the addition theorem of the chi-square distribution [14] we know the distribution of Eq. 25 will be chi-square distributed with $2 \mathrm{~N}$ degrees of freedom. Thus, if $n=2 \mathrm{~N}$ we can write the densily of Eq. 25 as:

$$
D_{N}(\gamma)=\frac{1}{z^{N} \sigma_{r}{ }^{N} \Gamma(N)} \Leftarrow y P\left(-\frac{\gamma}{2 \sigma_{r}^{2}}\right) \gamma^{N-1}
$$


What we actually wish to determine, however, is the density function of $\bar{W}$ where

$$
\bar{w}=\frac{1}{N} \gamma
$$

Making a change of variables we see

$$
P_{N}(\bar{w})=\frac{N^{N}}{2^{N} \sigma_{r}^{N} \Gamma(N)} \exp \left(-\frac{N \bar{w}}{2 \sigma_{r}^{2}}\right) \bar{W}^{N-1}
$$

which is a Gamma density function for $\bar{W}$.

Finding the expected value and variance of $\bar{W}$ in the usual fashion we obtain:

$$
\begin{aligned}
& \kappa[\bar{w}]=K_{\bar{w}}=2 \sigma^{2} \\
& V[\bar{w}]=\sigma_{\bar{N}}^{2}=\frac{4 \sigma_{F}}{N}
\end{aligned}
$$

\subsection{DETERMINATION OF THE NUMBER OF INDEPENDENT SAMPLES AVERAGED}

At this point we have shown that we expect the distribution of the return power from a target consisting of a complex of discrete scatterers to be describable by a Gamma density function. We will follow this assumption throughour the remainder of this report.

We must now determine a method from which the actual number of independent samples, N, can be calculated. From Eqs. 29 and 30 we see how this can be done, That is,

$$
\frac{\left(\mu_{\bar{n}}\right)^{2}}{\sigma_{\bar{w}}^{2}}=N
$$

Thus, we can determine $N$, the number of independent samples averaged if we can determine $\mu_{\bar{w}}$ and $\sigma_{\bar{w}}{ }^{2}$. These parameters were estimated in the usual fashion by employing Eqs. 32 and 33 :

$$
\hat{\mu}_{\nabla}=\frac{1}{m} \sum_{i=1}^{m} x_{i}
$$




$$
\hat{\sigma}_{\bar{w}}=\frac{1}{m} \sum_{i=1}^{m}\left(\frac{1}{w}-x_{i}\right)^{2}
$$

where $m$ is the number of measurements taken.

In the cases of corn, soybeans, and alfalfa, the number of measurements averaged was 140 and for bare ground 152 samples were averaged.

If we follow Eqs. 31 through 33 we can determine $N$. The results are shown in Table 2.

TABLE 2.

CALCULATED NUMBER OF INDEPENDENT SAMPLES, $N$, BASED ON MEASURED DATA

\begin{tabular}{lcccccr}
\hline $\begin{array}{l}\text { Incidence } \\
\text { Angle }\end{array}$ & $0^{\circ}$ & $10^{\circ}$ & $20^{\circ}$ & $30^{\circ}$ & $50^{\circ}$ & $70^{\circ}$ \\
\hline Bare Soil & 2.5 & 1.3 & 2.3 & 3.7 & 3.8 & 7.8 \\
Corn & 1.0 & 1.3 & 7.0 & 6.0 & 8.5 & 11.3 \\
Soybeans & 2.8 & 2.7 & 2.2 & 5.0 & 4.2 & 10.0 \\
Alfalfa & 1.7 & 2.1 & 1.8 & 2.5 & 5.2 & 8.3 \\
\hline
\end{tabular}

At the time of measurement, soil samples were taken in three layers to determine moisture content by weight. These layers as measured from the soil surface are: $0-1 \mathrm{~cm}, 1-2 \mathrm{~cm}$ and $2-5 \mathrm{~cm}$. The per cent moisture is shown in Table 3.

TABLE 3.

SOIL MOISTURE CONTENT BY WEIGHT

\begin{tabular}{lrrr}
\hline Depth (cm) & $0-1$ & $1-2$ & $2-5$ \\
\hline Bare Soil & $19 \%$ & $20 \%$ & $21 \%$ \\
Corn & $26 \%$ & $24 \%$ & $25 \%$ \\
Soybeans & $6 \%$ & $11 \%$ & $26 \%$ \\
Alfalfa & $18 \%$ & $25 \%$ & $19 \%$ \\
\hline
\end{tabular}


Let us now calculate the number of independent samples as predicted by Eq.

lb. The range resolution of the scatterometer used in this experiment is given in meters by :

$$
\Delta R=\frac{1.6 \sigma}{\cos \theta}
$$

where $\theta$ is the incidence angle. Thus if the maximum dimension, $D^{\prime}$, of the target as measured radially from the antennas is less than $\triangle R$, we will assume $D=D^{\prime}$ where $D$ is defined in Section 3. If, however, $D^{\prime}$ is greater than $\triangle R$ we will assume $D=\Delta R$. If complete penetration through the vegetation is assumed, then $D^{\prime}=H \sec \theta$, where $H$ is the vegetation height. For cases where no penetration is expected, $D^{\prime}$ is the difference between the maximum and minimum radial distances to the target as determined by the antenna beamwidth. Shown in Table 4 are the heights of the various crops at the time of the experiment.

TABLE 4.

\begin{tabular}{lc}
\hline Crop & Crop Height \\
\hline Soybeans & $0.36 \mathrm{~m}$ \\
Corn & $2.45 \mathrm{~m}$ \\
Alfalfa & $0.63 \mathrm{~m}$ \\
\hline
\end{tabular}

With the information of Table 4 and employing Eq. 37 it is possible to determine $\triangle \mathrm{f}$ as defined by Eq. Ib. Ray's model [8] wos chosen as it seems to be representative of the models discussed in Section 3.0. Knowing $\Delta f$ we can determine $\mathrm{N}$ by dividing the modulation bandwidth, $400 \mathrm{MHz}$, by the frequency spacing between independent samples, $\Delta f$. The results of this calculation are shown in Table 5. It was necessary to make certain assumptions concerning the amount of penetration taking place. Since corn and soybeans are both row crops, the radar return will normally have contributions from scatterers at various depths between the top of the plants and the ground. Hence total penetration was assumed. Alfalfa, however, is not a row crop and it was not immediately obvious as to what degree penetration occurred. For this case Table 5 shows two entries for alfalfa. The first entry, $\mathrm{N}_{z}$, assumes zero penetration while the second, $\mathrm{N}_{t}$, assumes total penetration. In the case of bare ground, no penetration was assumed due to its small skin depth at 20 per cent moisture content [15]. 
TABLE 5.

NUMBER OF INDEPENDENT SAMPLES,

$\mathrm{N}$, AS CALCULATED USING EQ.lb

\begin{tabular}{ccccccc}
\hline $\begin{array}{l}\text { Look } \\
\text { Angle }\end{array}$ & $\begin{array}{c}\text { Corn } \\
\mathrm{N}\end{array}$ & $\begin{array}{c}\text { Soybeans } \\
\mathrm{N}\end{array}$ & $\begin{array}{c}\text { Bare Ground } \\
\mathrm{N}\end{array}$ & $\mathrm{N}_{z}$ & $\mathrm{~N}_{t}$ \\
\hline $0^{\circ}$ & 4.08 & 0.959 & 0.026 & 0.026 & 1.7 \\
$10^{\circ}$ & 4.15 & 1.6 & 0.694 & 0.694 & 2.3 \\
$20^{\circ}$ & 4.34 & 2.42 & 1.39 & 1.39 & 3.2 \\
$30^{\circ}$ & 4.72 & 3.50 & 2.08 & 2.08 & 4.4 \\
$40^{\circ}$ & 5.34 & 5.25 & 4.16 & 4.16 & 6.1 \\
$50^{\circ}$ & 6.34 & 6.34 & 6.34 & 6.34 & 6.34 \\
$60^{\circ}$ & 8.16 & 8.16 & 8.16 & 8.16 & 8.16 \\
$70^{\circ}$ & 11.76 & 11.76 & 11.76 & 11.76 & 11.76 \\
\hline
\end{tabular}

The reason for $\mathrm{N}$ being the same for all crops at angles past $40^{\circ}$ is that the range resolution of the radar is dependent solely on incidence angle for angles of $50^{\circ}, 60^{\circ}$ and $70^{\circ}$.

\subsection{DATA INTERPRETATION}

In order to facilitate interpretation of the data, it is presented in a graphical format of three types. The first is in the form of histograms of the measured scattering coefficient, $\sigma^{\circ}$, and are presented in Appendix A. To more easily see the effects of averaging, each point was divided by the mean value of $\sigma^{\circ}$ at each angle for that particular target. This insured that the mean occurred at a value $\sigma^{\circ}=1$ for all histograms. Although this is merely a qualitative tool, it does show the effect of averaging as the incidence angle increases from $0^{\circ}$ to $70^{\circ}$. Note that the distributions do indeed look chi-square in appearance, as was predicted in Section 4.0. Figure 4 shows the mean value of $\sigma^{\circ}$ plotted versus incidence angle for each of the four targets under discussion. 

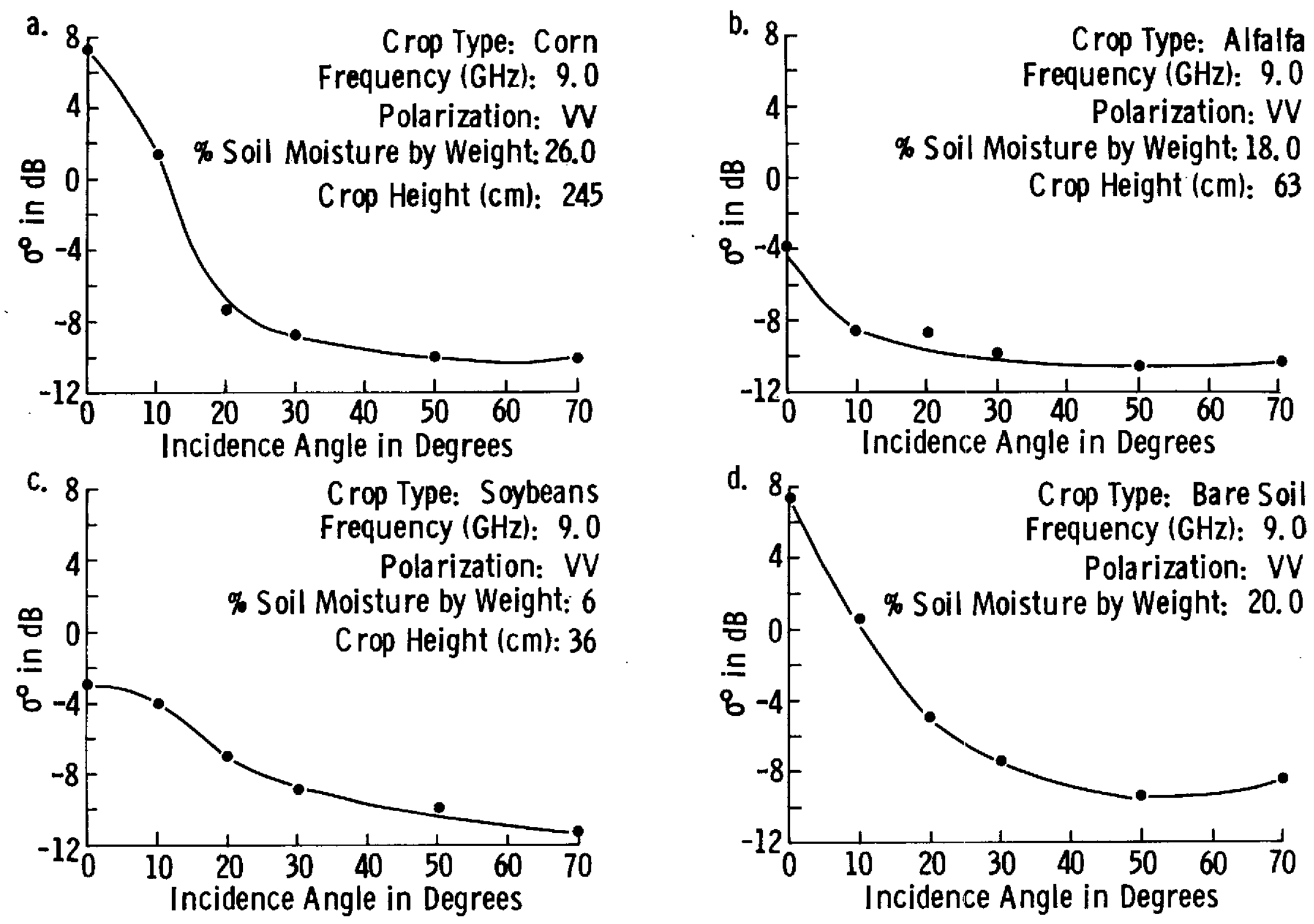

Figure 4. Scattering coefficient, $\sigma^{\circ}$, versus incidence angle, $\theta$. a) corn b) alfalfa c) soybeans d) bare soil 
The last method of data presentation which gives a more quantitative description of the averaging process is that of plotting the data in Tables 2 and 5 on the same scale. This is done in Figures 5 through 8 . Since the histograms do have some empty spaces in them, it was felt that a smooth curve would be a better representation than actually joining the points by lines in a rather absolute manner. It should be noted that when Eq. Ib predicts less than one sample, the value was elevated to a value of one since less than one sample is physically unreal.

We begin by noting that Ray's model [8] is a fairly good predictor of $N$ for soybeans and bare ground. The trend is very close to the trend of the experimental results and the absolute values of the two curves are fairly consistent with one another. This is not the case for corn, however. The experimental curve for corn exhibits a sharp dip for values of $\theta$ less than $25^{\circ}$. This is attributed to an incorrect assumption concerning the degree to which the corn contributes to the measured return. If, for example, we assume that at small incidence angles the return is due mainly to the soil, we can understand why the curve exhibits the tendencies we see. This is to say that at small incidence angles we are "seeing" mostly the underlying soil. At larger incidence angles, however, the corn significantly attenuates the signal so that the effect of the soil is insignificant to the total return.

This hypothesis is supported by two facts. First we see in Table 3 that the soil was very wet underneath the corn; 26 per cent moisture by weight. This fact, combined with the fact that corn is a row crop and thus not as dense as a crop such as alfalfa or wheat, rends to augment the effect the soil will have on the scattered signal. Secondly, we can see from Figure 9 the effect of increasing the incidence angle on the return from corn with wet underlying soil. These curves show the tendencies of $\sigma^{\circ}$ as a function of look angle for soils with moisture contents of $42.0 \%, 18.7 \%$ and $4.5 \%$ [17]. The tendency for the curves to merge at angles greater than $30^{\circ}$ indicates the signal from the soil is greatly reduced by the corn at these higher angles while at smaller angles the soil return dominates.

Looking at the experimental and theoretical curves for alfalfa we see another interesting result. Note that two curves for Ray's model have been plotted. One assumes no penetration into the crop while the second assumes penetration down to the ground. At zero degrees, both curves predict the same result and they also agree with the experimental results. As the incidence angle increases, however, the curve assuming total penetration begins to deviate quite drastically from the experimental 


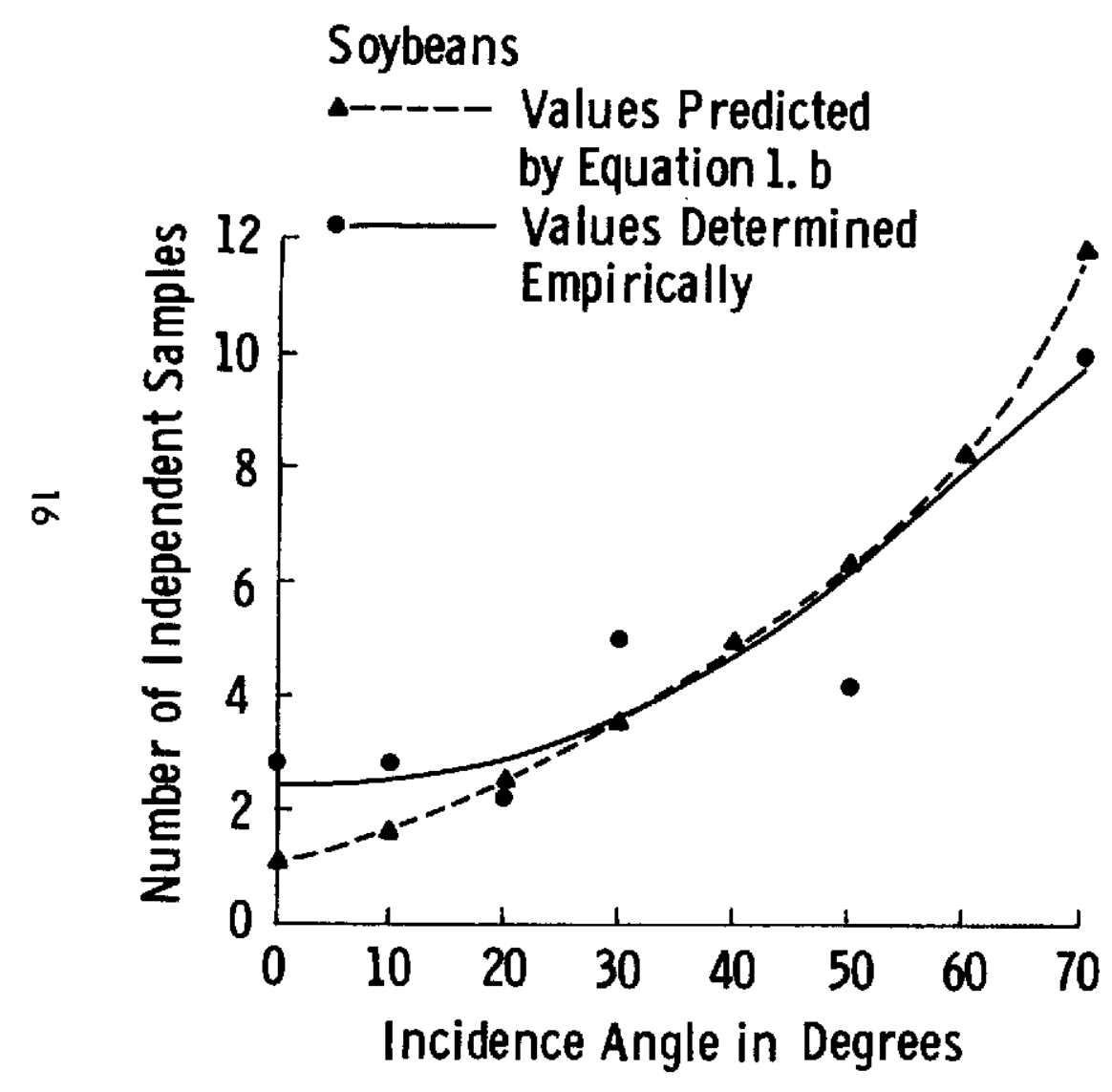

Figure 5.

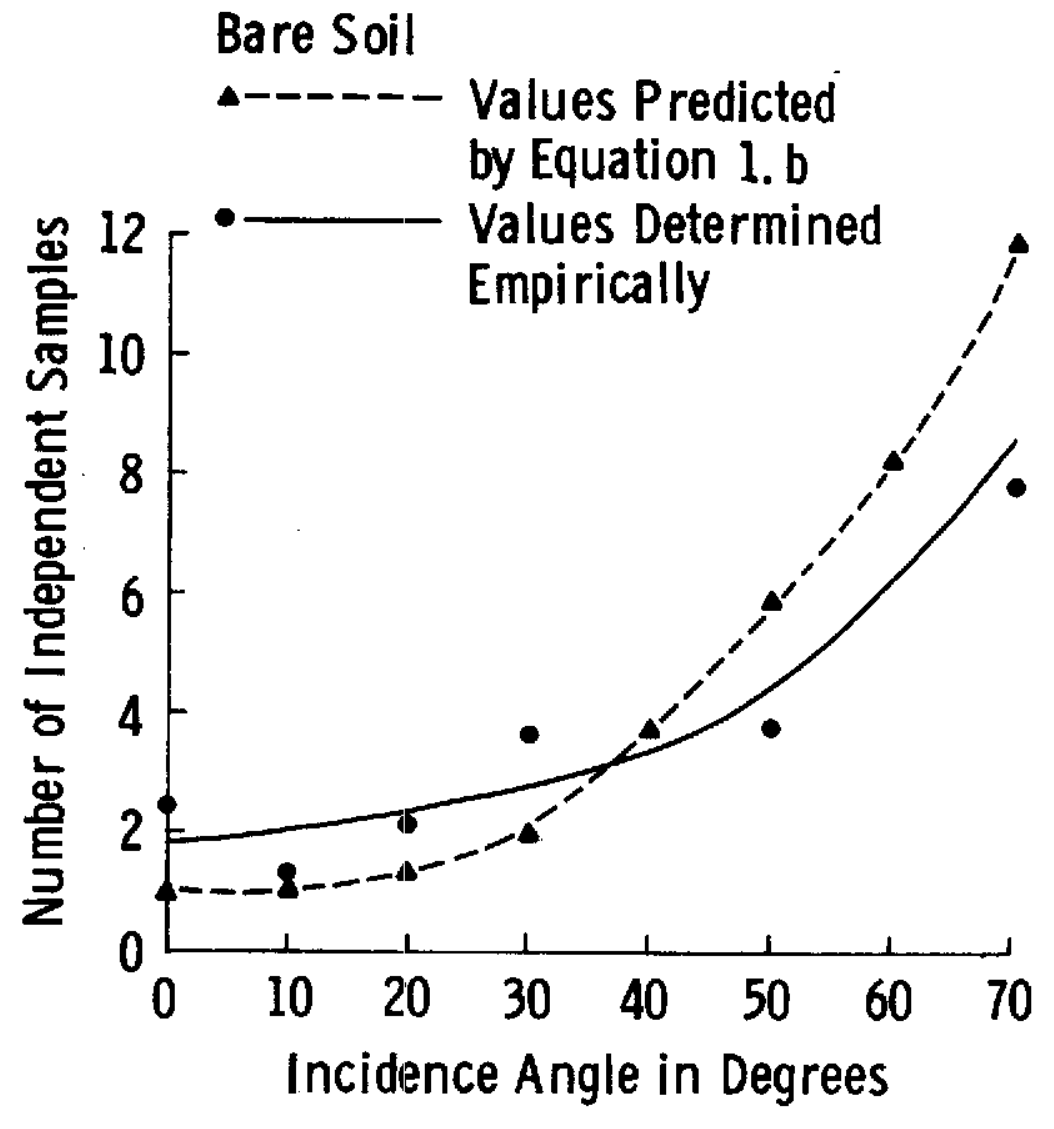

Figure 6. 


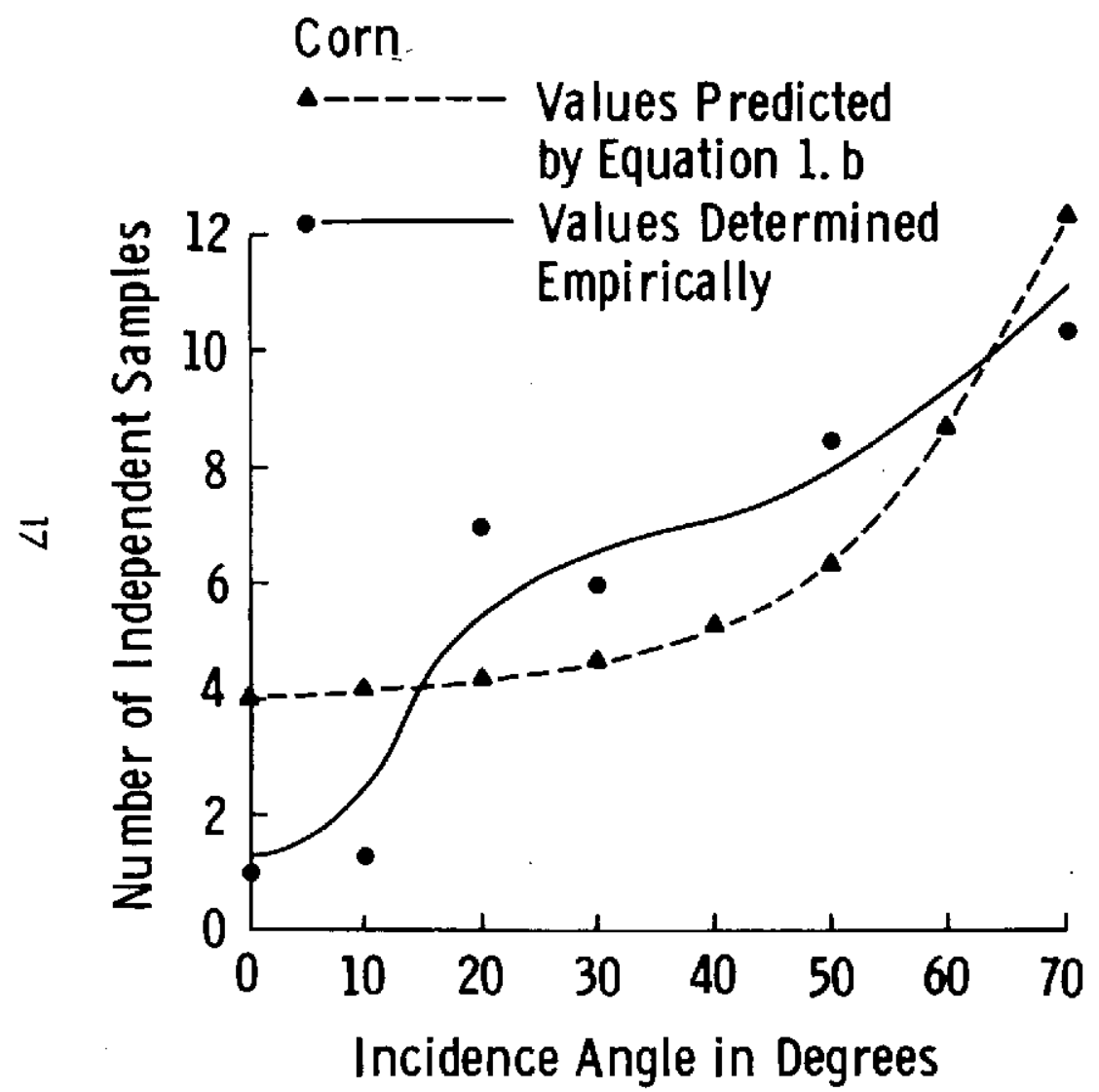

Figure 7.

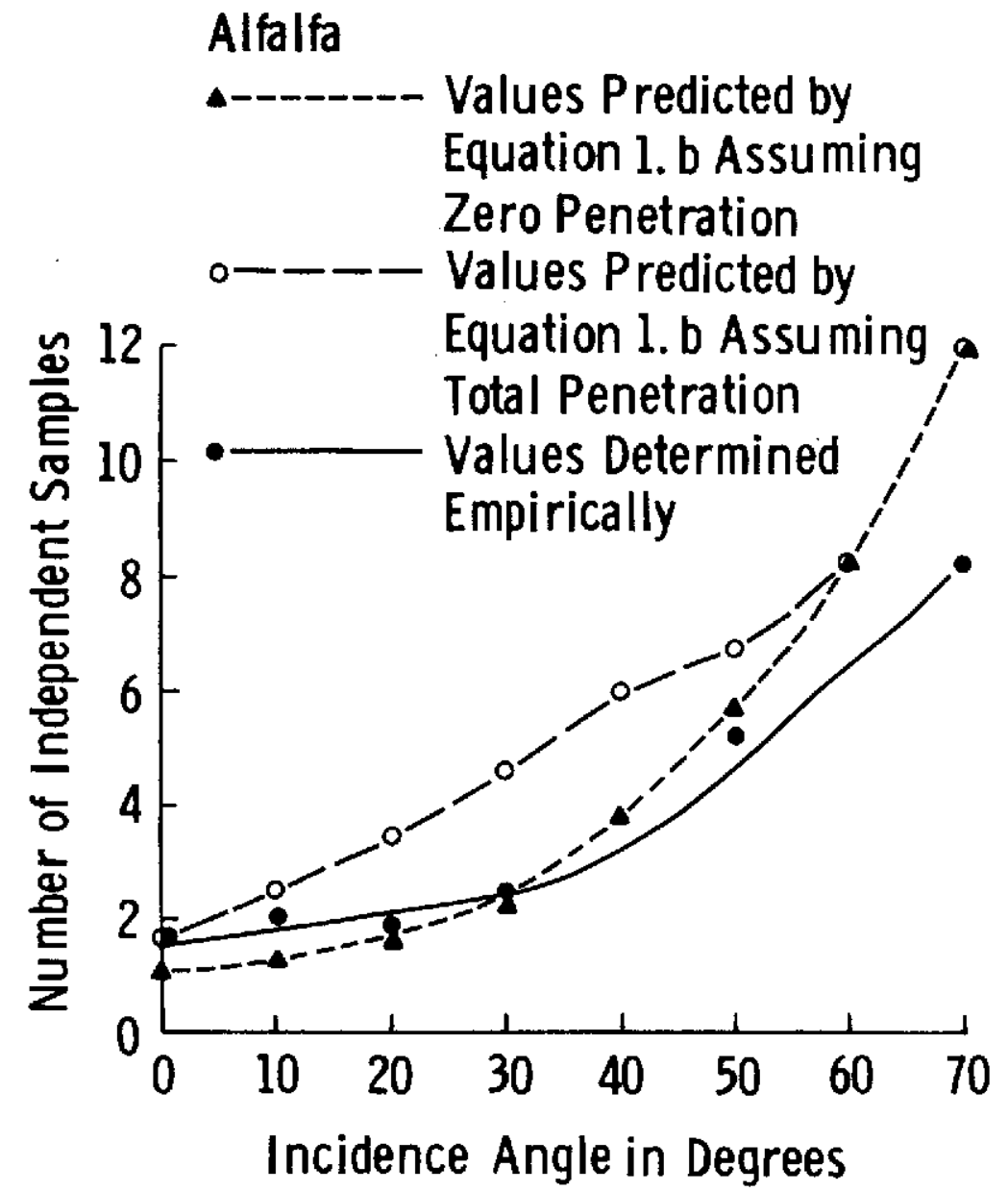

Figure 8 . 


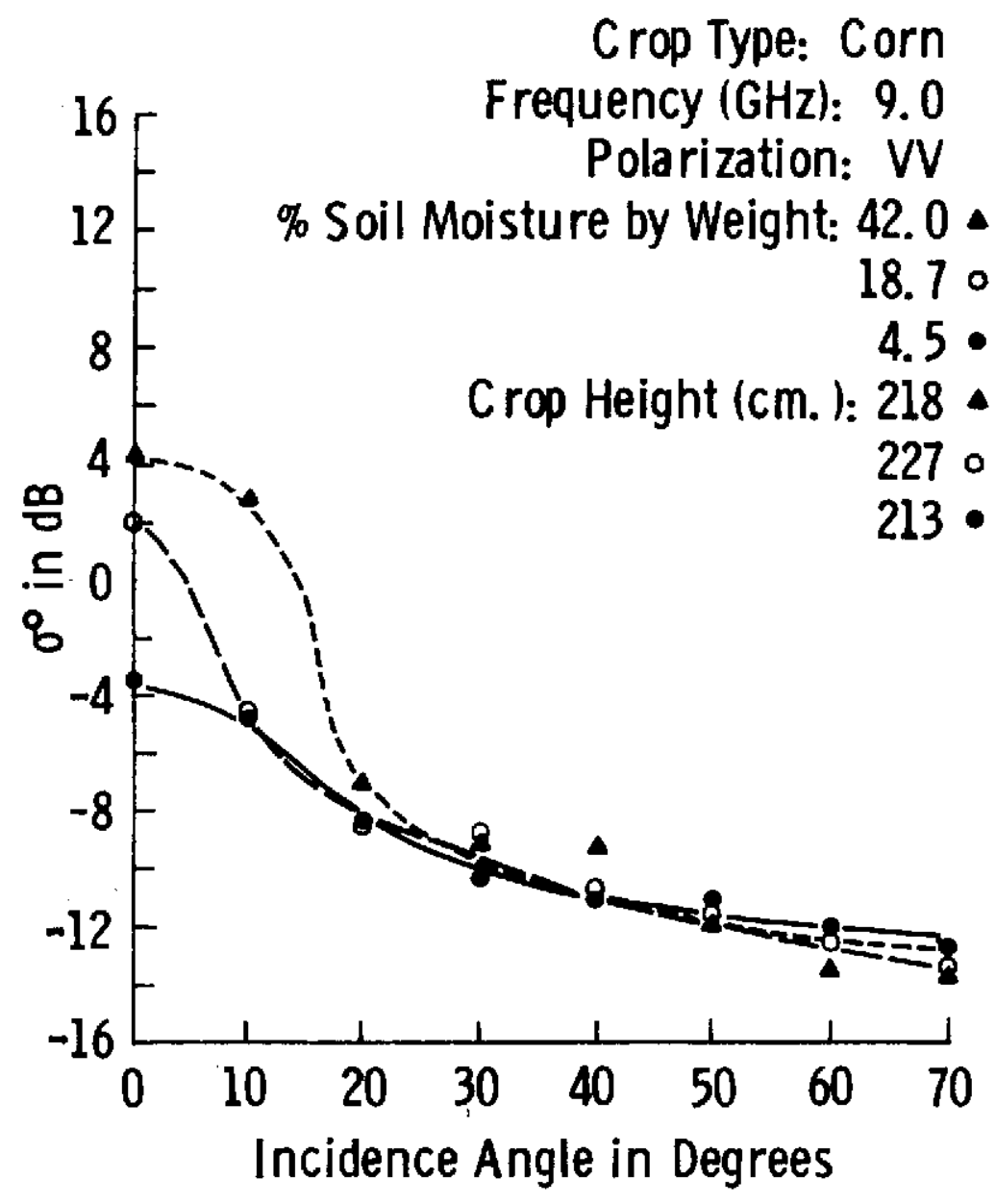

Figure 9. Scattering coefficient,$\sigma^{\circ}$ versus incidence angle, $\theta_{1}$ for corn with varying soil moistures. 
curve while the second theoretical curve tends to be comporable to the measured result.

Thus it seems that scatter from alfalfa tends to be a result of surface scatter rather than volume scatter. This effect had been noted earlier by Ulaby [16] in his studies of the angular dependence of $\sigma^{\circ}$ for different crop types.

\subsection{CONCLUDING REMARKS}

An experiment was performed to determine the fading characteristics of radar backscatter from agricultural targets. The assumption was made throughout the study that the distribution of the fading amplitude of radar backscatter from vegetation can be closely approximated by a Rayleigh distribution. For this assumption to be correct the target must consist of many random and independent scatterers. For naturally occurring vegetation such as a wooded area this is probably a good assumption. For agricultural vegetation, however, this may not be the case. Corn, soybeans and even bare cultivated fields are normally prepared and planted in a very orderly fashion by the farmer. The resulting geometric regularity produced may then make the validity of the Rayleigh assumption somewhat questionable. Schuchman and Drake [18] have reported that row orientation plays an important role in radar return from corn. The assumption may also break down for bare cultivated soil in which case a good probability of specular scatter exists at angles near nadir.

Another phenomena that should be investigated is that of signal refraction by the vegetation. This may be particularly important at angles away from nadir in which case a small amount of refraction may produce a relatively large change in the effective target extent. In addition to refraction, target penetration has been shown to play a significant role in altering effective target extent, thus affecting the fading process.

Implementation of a non-coherent radar would provide more quantitative information on the range of validity of the Rayleigh assumption. A comparison of the fading process as measured by such a system to that as measured by a coherent system would then answer many of the questions as to the types of targets which have previously been assumed to scatter radar signals incoherently. 
APPENDIX A

HISTOGRAMS OF THE POWER DISTRIBUTIONS OF

RADAR BACKSCATTER FROM BARE GROUND, SOYBEANS, CORN AND ALFALFA 

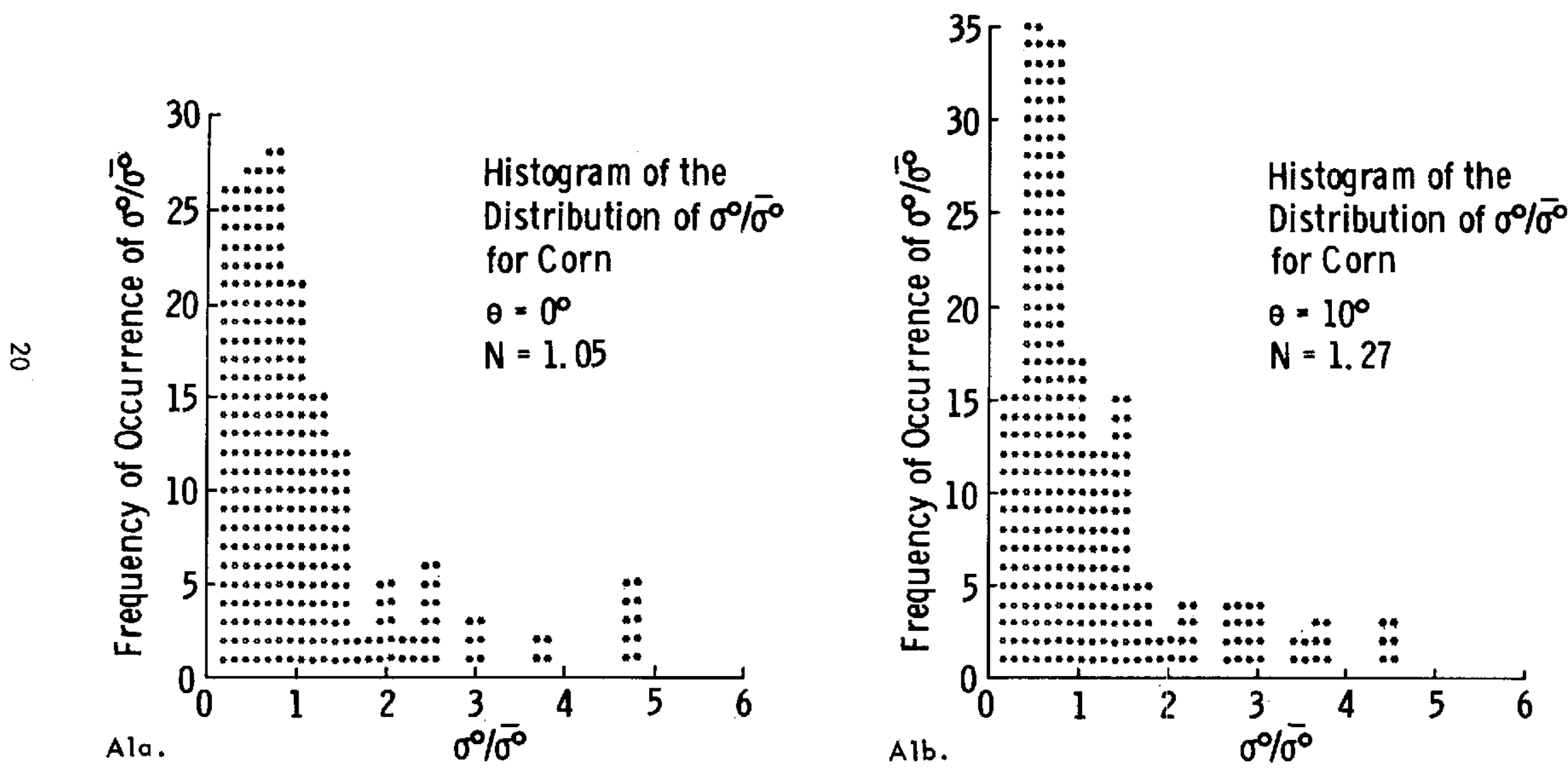

Figures A la. - Alb. Histograms of $\sigma^{\circ}$ for corn normalized by $\bar{\sigma}^{\circ}$, the mean value of $\sigma^{\circ}$ 

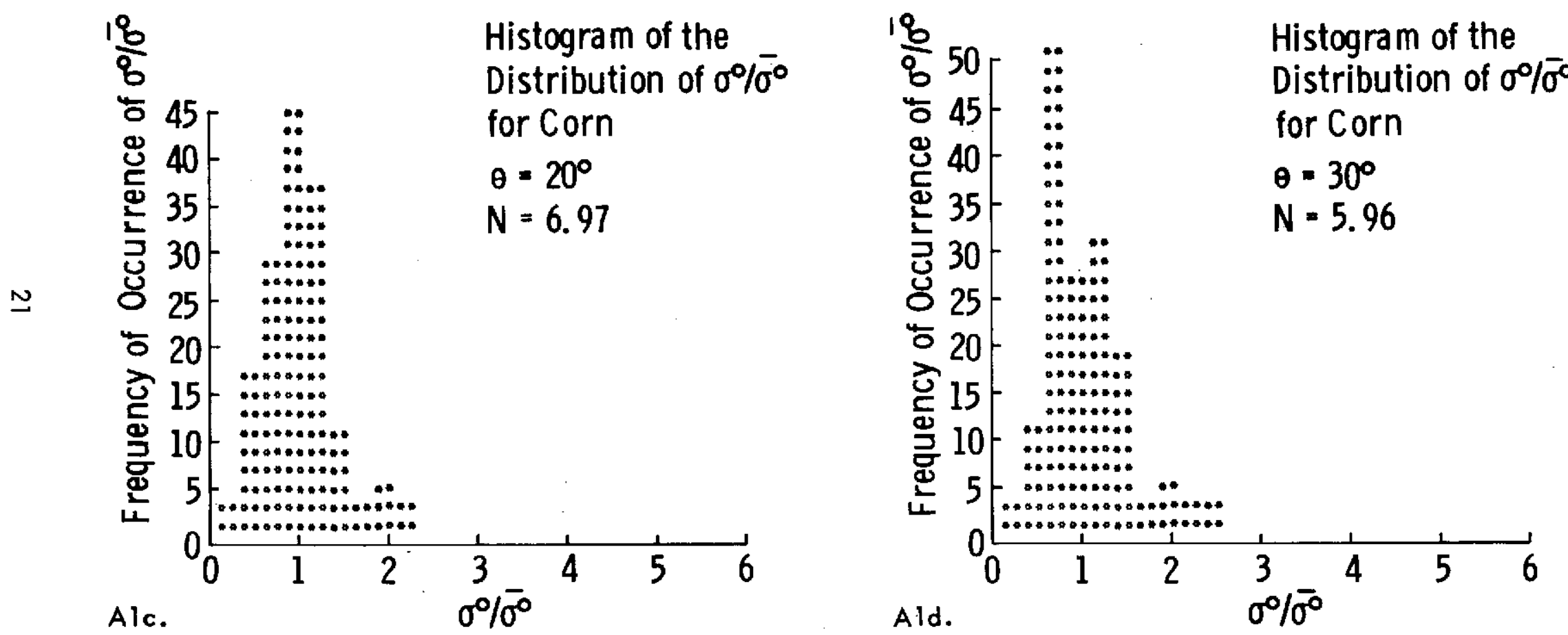

Figures Alc. - Ald. Histograms of $\sigma^{\circ}$ for corn normalized by $\bar{\sigma}^{\circ}$, the mean value of $\sigma^{\circ}$ 

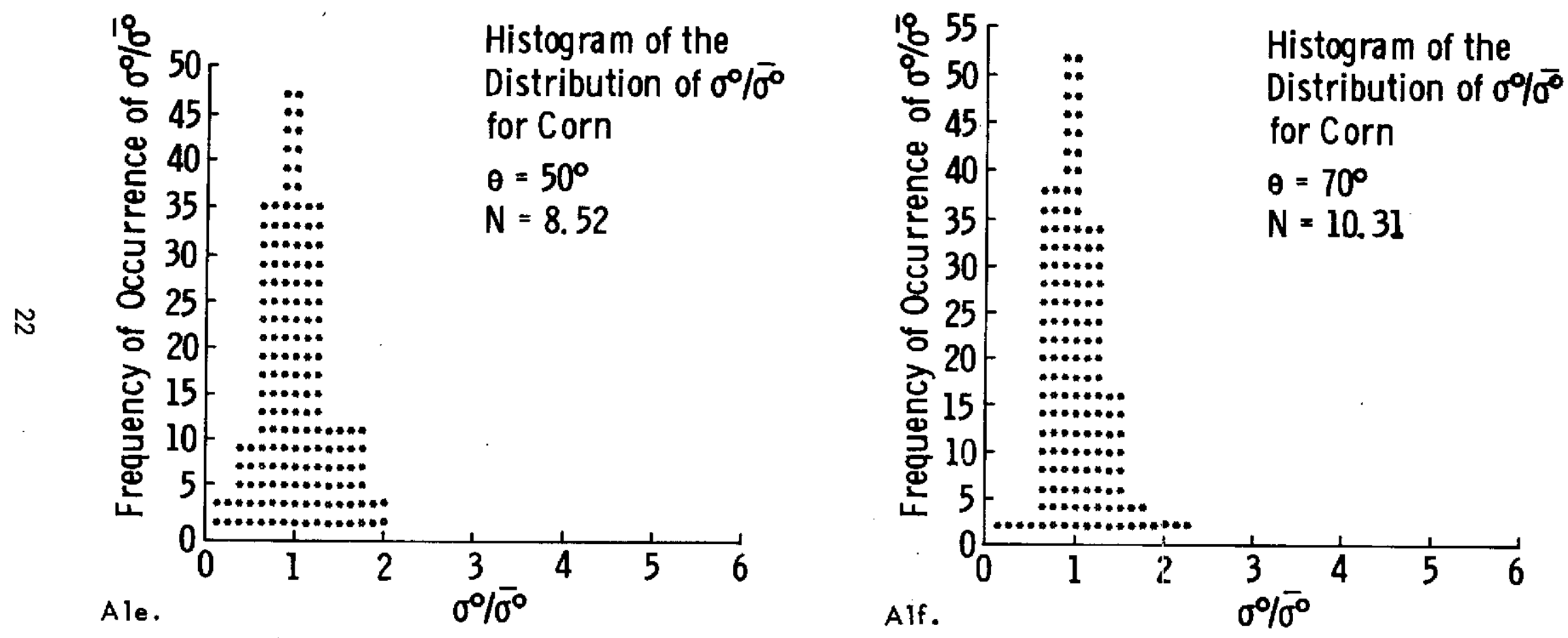

Figures Ale. - Alf. Histograms of $\sigma^{\circ}$ for corn normalized by $\bar{\sigma}^{\circ}$, the mean value of $\sigma^{\circ}$ 

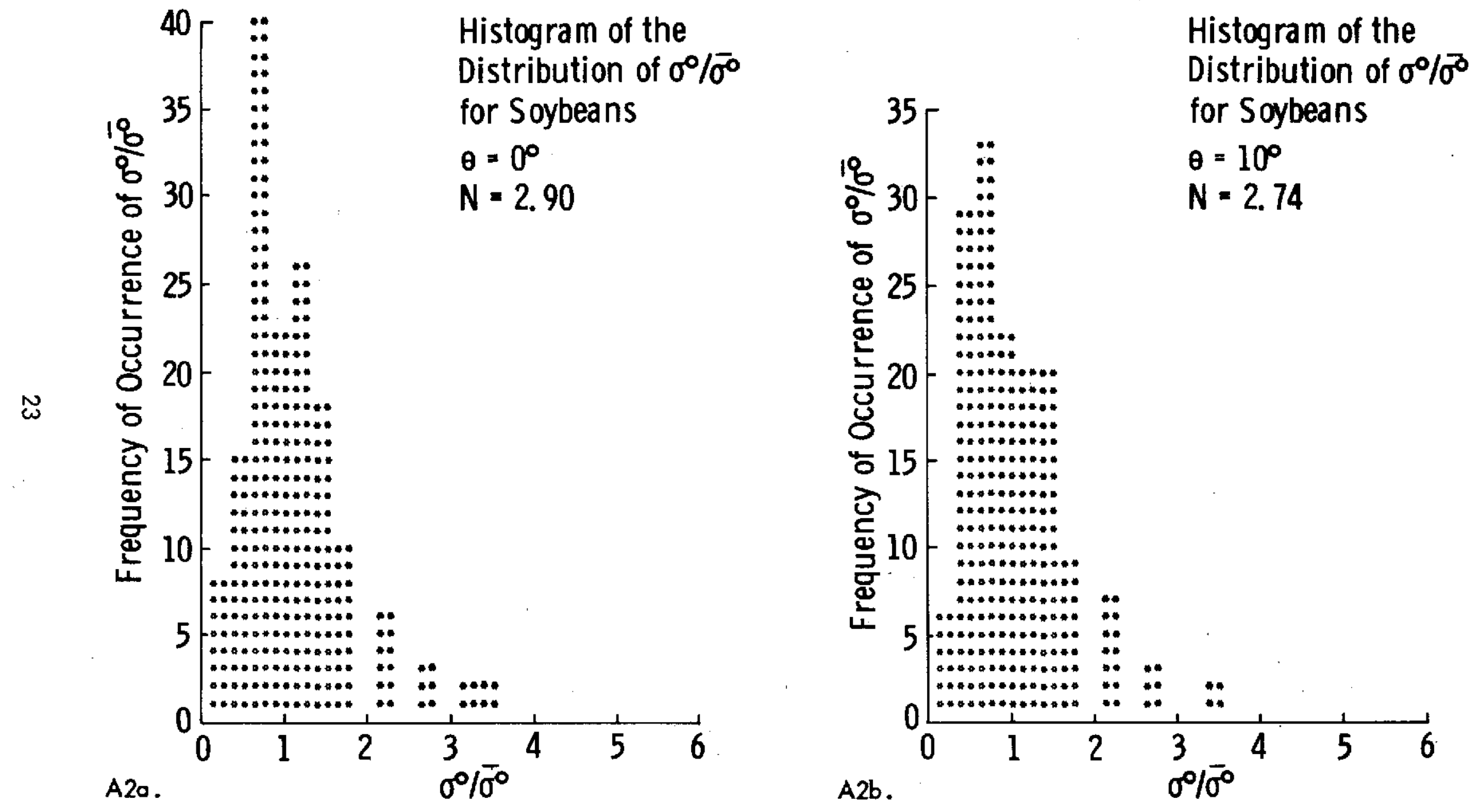

Figures A2a. - A2b. Histograms of $\sigma^{\circ}$ for soybeans normalized by $\bar{\sigma}^{\circ}$, the mean value of $\sigma^{\circ}$ 

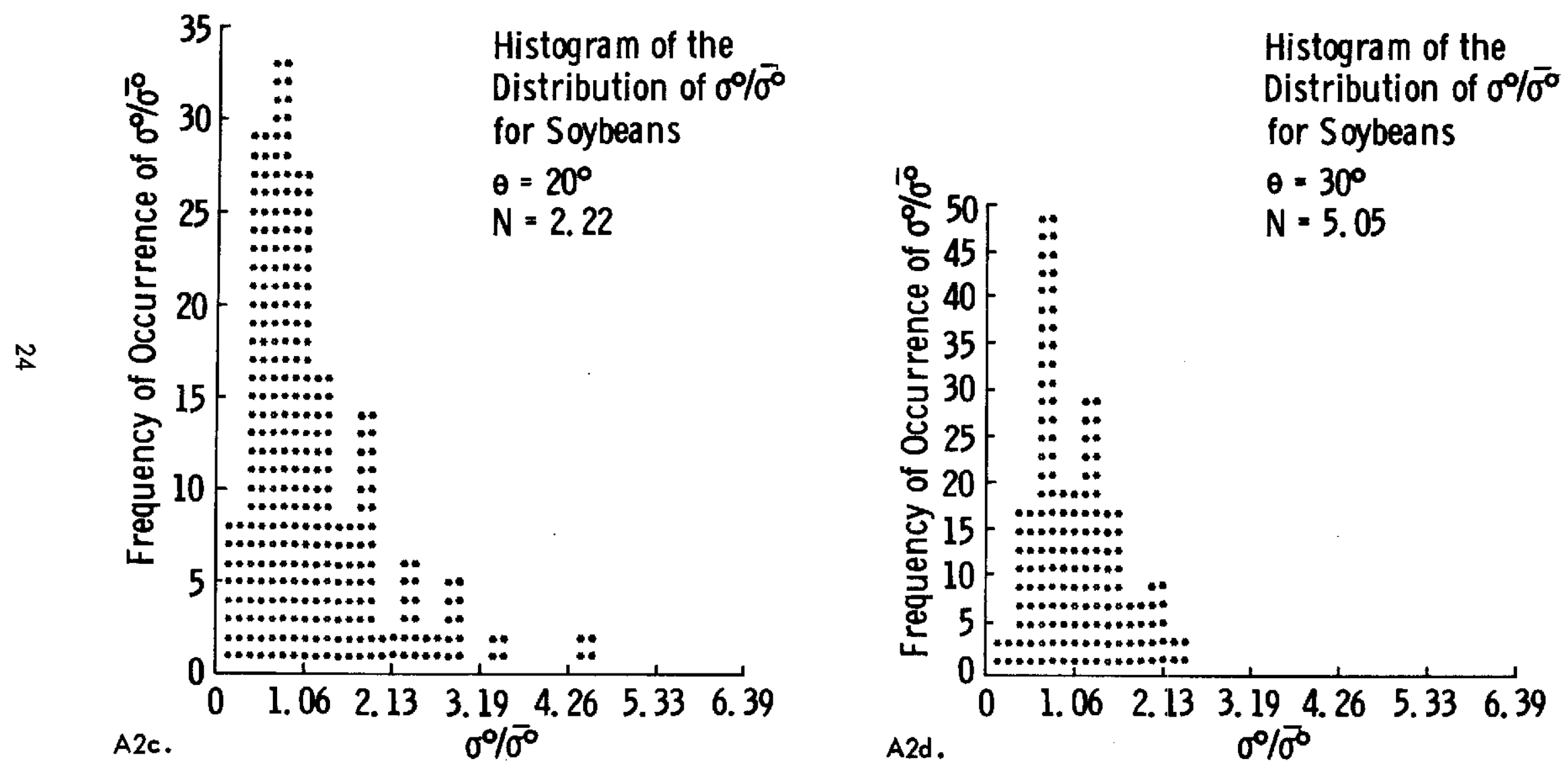

Figures A2c. - A2d. Histograms of $\sigma^{\circ}$ for soybeans normalized by $\bar{\sigma}^{\circ}$, the mean value of $c r^{\circ}$ 

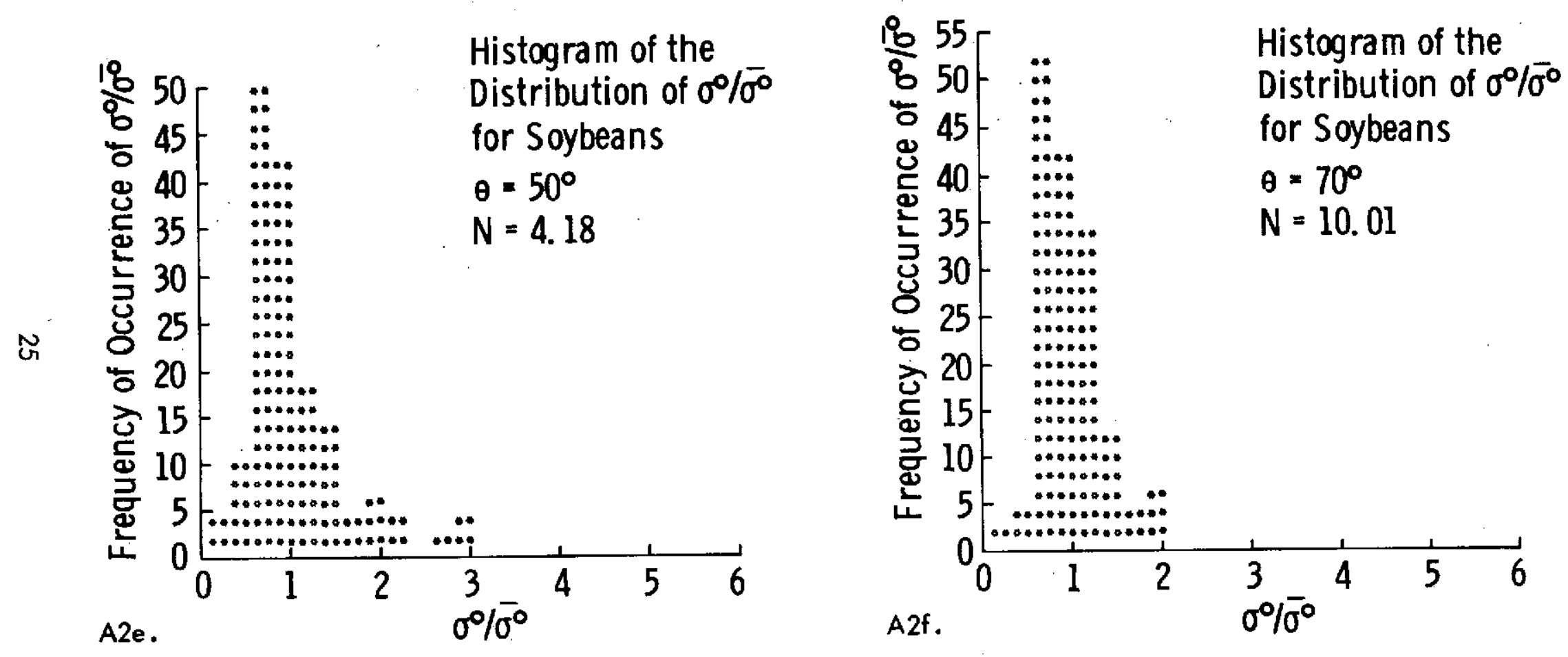

Figures A2e - A2f. Histograms of $\sigma^{\circ}$ for soybeans normalized by $\bar{\sigma}^{\circ}$, the mean value of $\sigma^{\circ}$ 

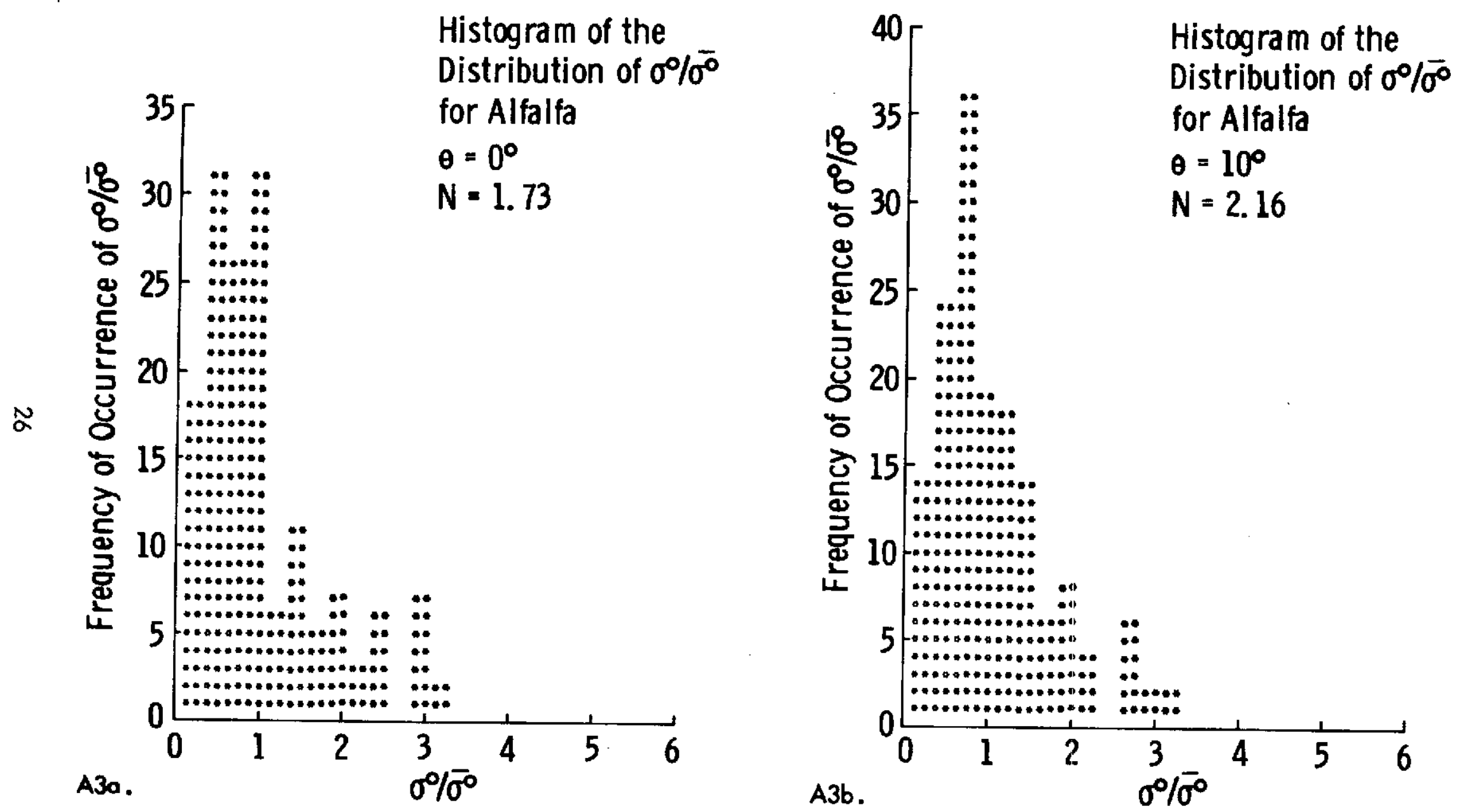

Figures A3a. - A3b. Histograms of $\sigma^{\circ}$ for Alfalfa normalized by $\bar{\sigma}^{\circ}$, the mean value of $\sigma^{\circ}$ 

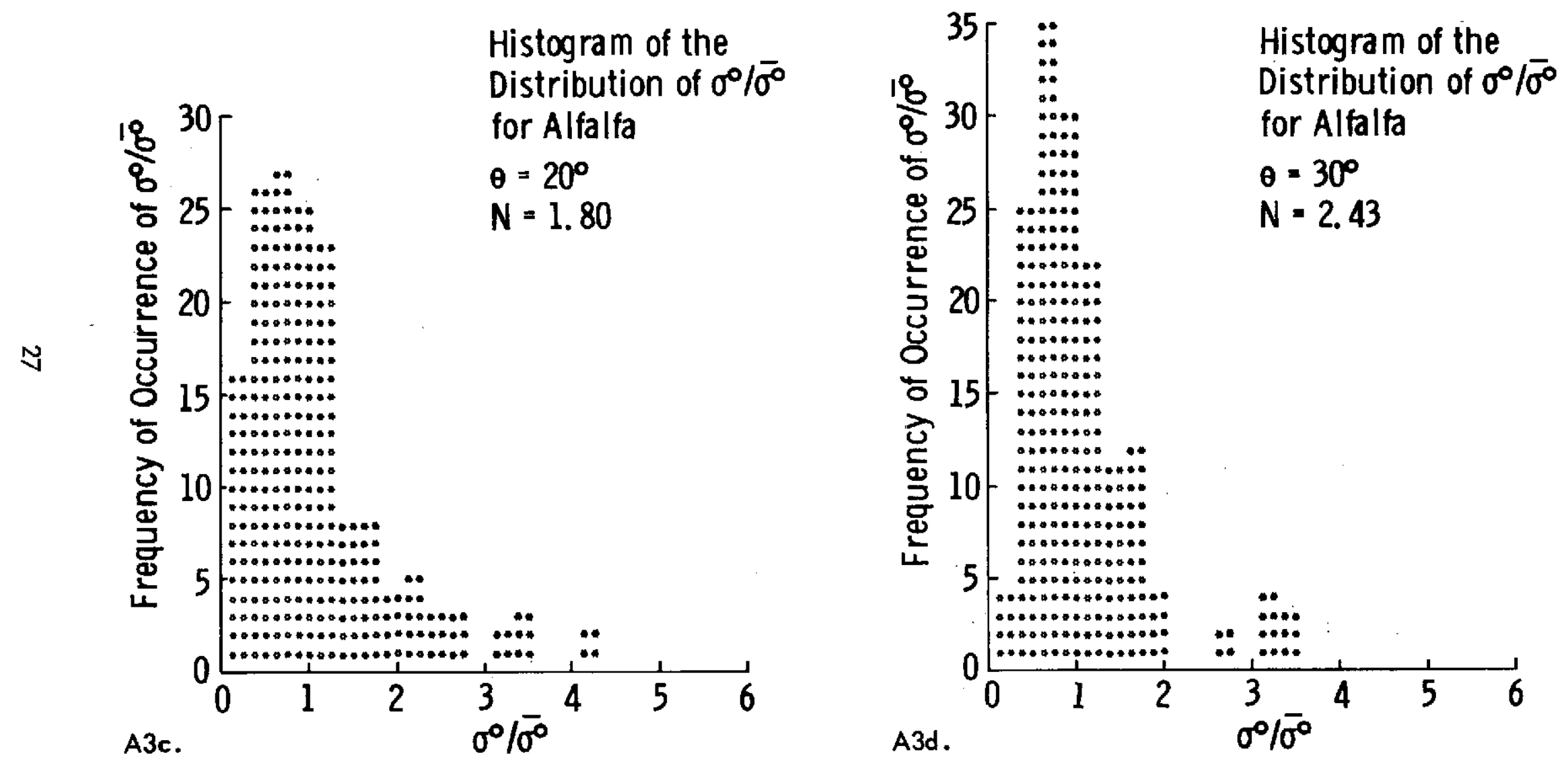

Figures A3c. - A3d. Histograms of $\sigma^{\circ}$ for alfalfa normalized by $\bar{\sigma}^{\circ}$, the mean value of $\sigma^{\circ}$ 

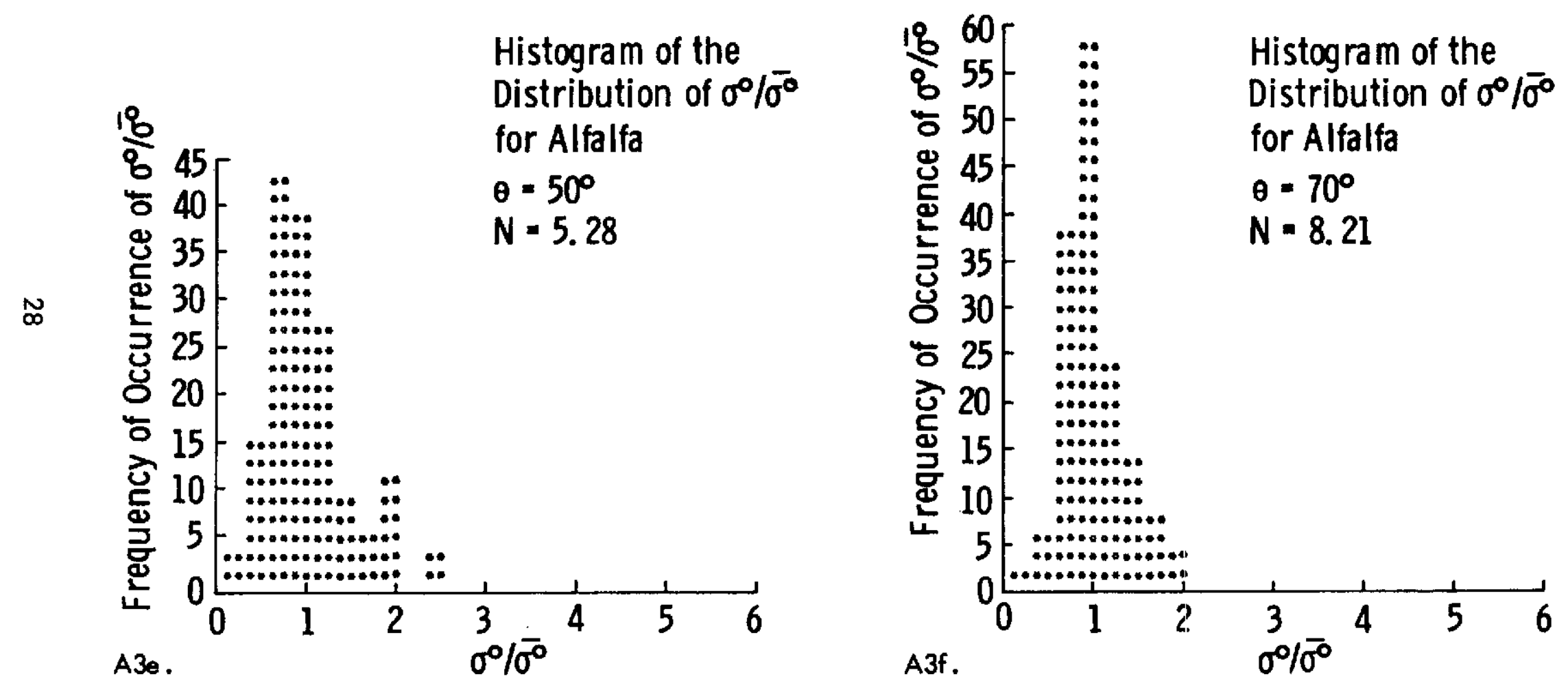

Figures A3e.- A3f. Histograms of $\sigma^{\circ}$ for alfalfa normalized by $\bar{\sigma}^{\circ}$, the mean value of $\sigma^{\circ}$ 

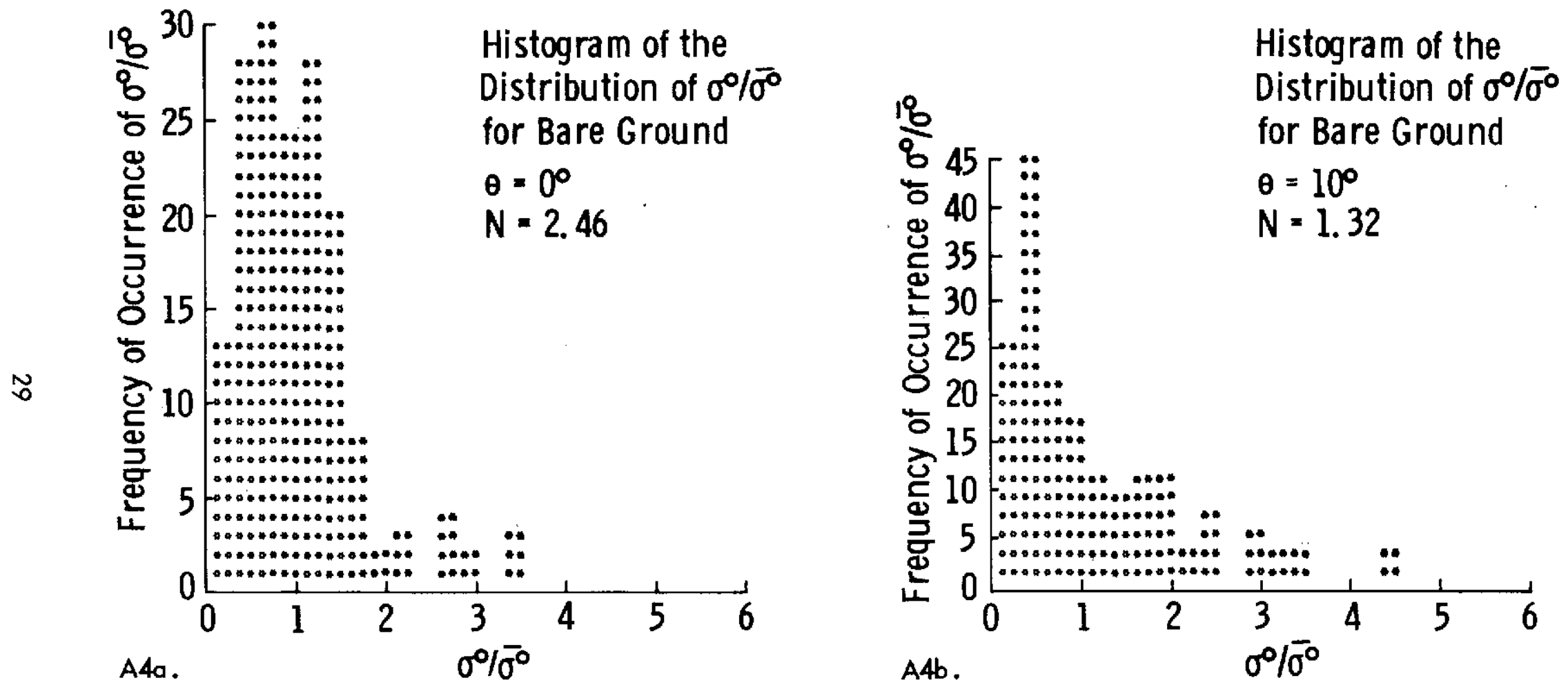

Figures A4a. - A4b. Histograms of $\sigma^{\circ}$ for bare ground normalized by $\bar{\sigma}^{\circ}$, the mean value of $\sigma^{\circ}$ 

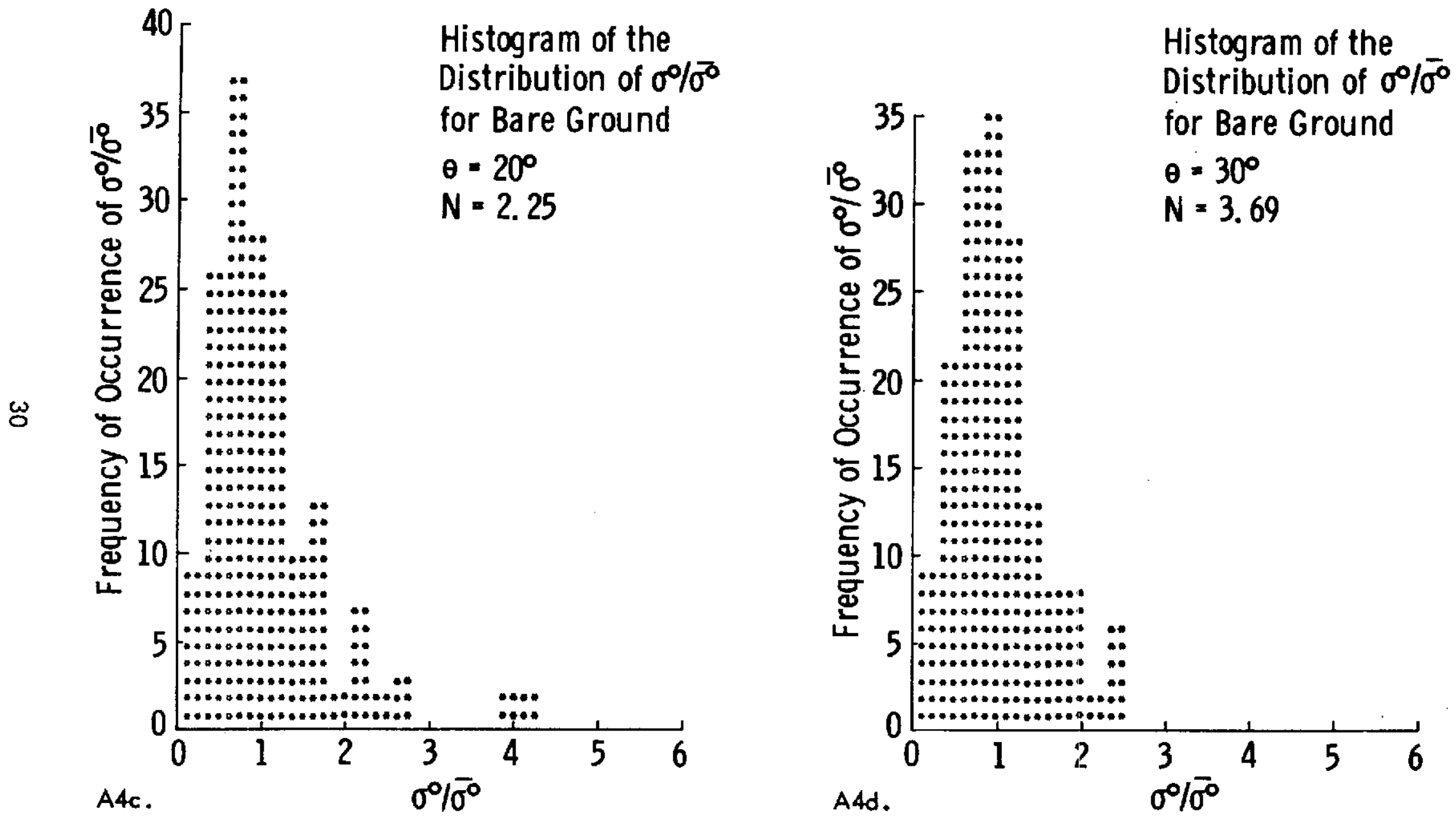

Figures A4c. - A4d. Histograms of $\sigma^{\circ}$ for bare ground normalized by $\bar{\sigma}^{\circ}$, the mean value of $\sigma^{\circ}$ 

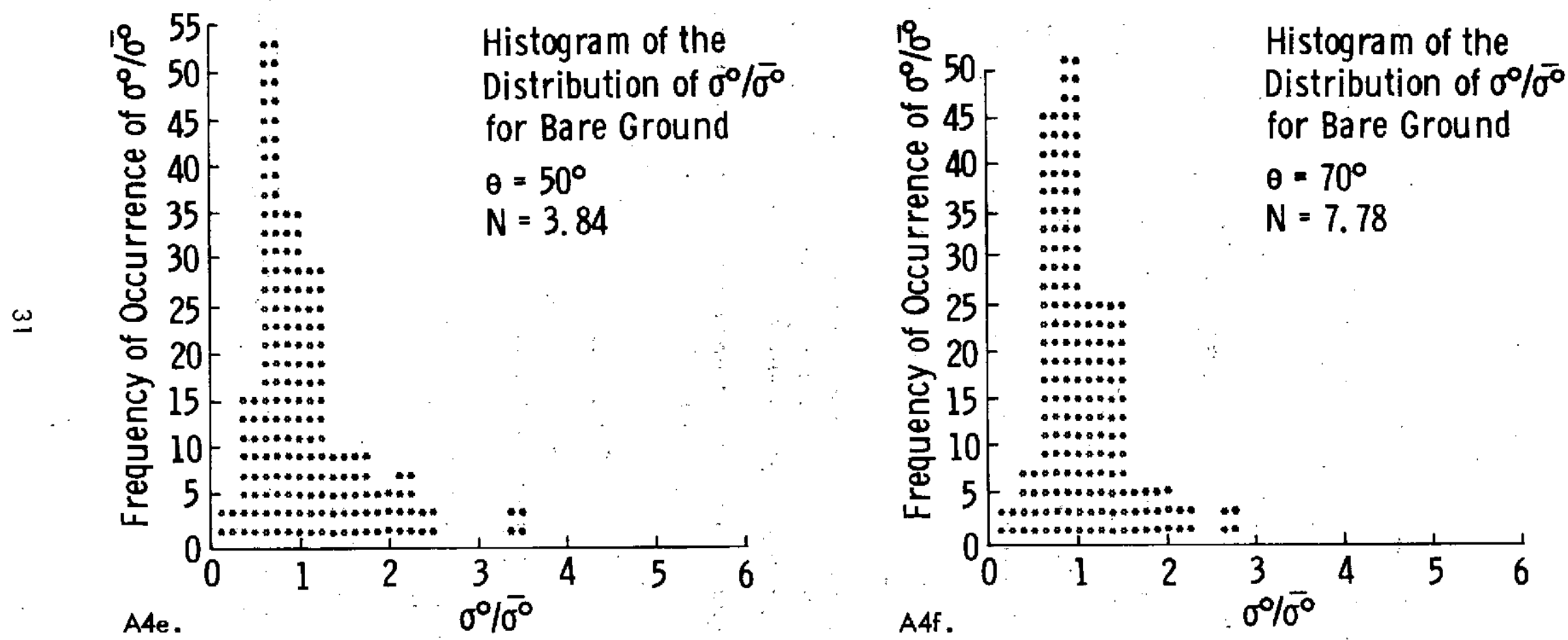

Figures A4e. - A4f. Histograms of $\sigma^{\circ}$ for bare ground normalized by $\bar{\sigma}^{\circ}$, the mean value of $\sigma^{\circ}$ 


\section{REFERENCES}

1. Lawson, J. L. and G. E. Uhlenbeck (eds.), "Threshold Signals, "MIT Radiation Laboratory Series, vol. 24, McGraw-Hill Book Co., New York, 1950.

2. Swerling, P., "Probability of Detection for Fluctuating Targets," IRE Transactions, vol. IT-6, pp. 269-308, April, 1960.

3. Fehlner, L. F., "Marcum and Swerling's Data on Target Detection by a Pulsed Radar," Johns Hopkins University Applied Physics Laboratory Report TG-45I, July, 1962, and Supplement, TG-45TA, September, 1964.

4. Heidbreder, G.R. and R. L. Mitchell, "Detection Probabilities for Log-Normally Distributed Signals," IEEE Transactions, vol. AES-3, pp. 5-13, January, 1967.

5. de Loor, G. P., "Radar Ground Returns Part IIl: Further Measurements on the Radar Backscatter of Vegetation and Soils," Physics Laboratory INO, Report No. PHL-974-05, The Hague, The Netherlands, March, 1974.

6. Bush, T. F. and F. T. Ulaby, "8-18 GHz Radar Spectrometer," University of Kansas Center for Research, Inc., CRES Technical Report 177-43, Lawrence, Kansas, September, 1973.

7. Birkemeir, W. P. and N. D. Wallace, "Radar Tracking Accuracy Improvement by Means of Pulse-to-Pulse Frequency Modulation," IEEE Transactions on Communication and Electronics, pp. 571-575, January, 1963.

8. Ray, H. K., "Improving Radar Range and Angle Detection with Frequency Agility," Microwave Journal, pp. 63-68, May, 1966.

9. Moore, R. K., W. P. Waite and J. W. Rouse, Jr., "Panchromatic and Polypanchromatic Radar," Proceedings IEEE, vol. 57, pp. 590-593, 1969.

10. Waite, W. P., "Broad Spectrum Electromagnetic Backscatter," University of Kansas Center for Research, Inc., CRES Technical Report 133-17, Lawrence, Kansas, August, 1970.

11. Beckmann, P., Probability in Communication Engineering, Harcourt, Brace and World, New York, pp. 113-119, 1967.

12. Breipohl, A. M., Probabilistic Systems Analysis, John Wiley and Sons, Inc., New York, p. 148, 1970.

13. Wozencraft, J. M. and 1. M. Jacobs, Principles of Communication Engineering, John Wiley and Sons, New York, pp. 58-63, 1965. 
14. Cramer, H., Mathematical Methods of Statistics, Princeton University Press, p. 234,1946 .

15. Ulaby, F. T., J. Cihlar and R. K. Moore, "Active Microwave Measurement of Soil Water Content," University of Kansas Center for Research, Inc., CRES Technical Report 177-46, Lawrence, Kansas, November, 1973.

16. Ulaby, F. T., "Radar Response to Vegetation," University of Kansas Center for Research, Inc., CRES Technical Report 177-42, Lawrence, Kansas, Seprember, 1973.

17. Ulaby, F. T., T. Bush and P. Batlivala, "The Effects of Soil Moisture on the Radar Backscatter from Vegetation," University of Kansas Center for Research, Inc., CRES Technical Report 177-51, Lawrence, Kansas, July, 1974.

18. Schuchman, R. A. and B. Drake, "Feasibility of Using Multiplex SLAR Imagery for Water Resource Management and Mapping Vegetation Communities," Proc. 9th International Symposium on Remote Sensing of Environment, Ann Arbor, University of Michigan, April, 1974. 


\section{CRINC LABORATORIES}

Chemical Engineering Low Temperature Laboratory

Remote Sensing Laboratory

Flight Research Laboratory

Chemical Engineering Heat Transfer Laboratory

Nuclear Engineering Laboratory

Environmental Health Engineering Laboratory

Information Processing Laboratory

Water Resources Institute

Technology Transfer Laboratory 